\title{
NGHIÊN CỬU ĐÁNH GIÁ KHẢ NĂNG CHỊU HẠN CỦA MỘT SỐ GIỐNG LÚA LAI THÍCH HỢP CHO VÙNG ĐỒI NÚI BẮC TRUNG BỘ NHẰM THÍCH ƯNG VỚI BIẾN ĐỔI KHÍ HậU
}

\author{
Phạm Thị Thanh Hương1, Nguyễn Thị Hoàng Anh², Lê Thị Hường ${ }^{1}$, Vũ Thị Hạnh ${ }^{1}$
}

Tóm tắt: Thí nghiệm được thực hiện trong năm 2017 tại 3 tỉnh vùng Bắc Trung Bộ nhằm đánh giá khả năng chịu hạn và sinh truởng của 8 giống lúa lai thu thập trong vùng. Khả năng chịu hạn của các giống lúa được đánh giá trong điều kiện nhân tạo bằng cách xử lý hạt trong dung dịch Polyethylen glycol $20 \%$ và bố trí thí nghiệm ngoài đồng ruộng. Kết quả cho thấy giống Thái Xuyên 111 có tỷ lệ nảy mầm cao, mầm và rễ vẫn phát triển tốt trong điều kiện hạn nhân tạo. Giống có thời gian sinh truơong trung bình, chịu hạn tốt, cho năng suất khá ở điều kiện không chủ động tuơơi. Năng suất lúa đạt 72,33 tạ/ha trong vu xuân và 70,55 tạ/ha trong vu mùa. Đây là giống có tiềm năng để đua vào gieo cấy cho các vùng đồi núi khó khăn về nước tại Bắc Trung Bộ.

Tù̀ khóa: Lúa lai, giống chịu hạn, Bắc Trung Bộ, không chủ động tuới.

Ban Biên tập nhận bài: 12/08/2019 Ngày phản biện xong: 08/10/2019 Ngày đăng bài:25/10/2019

\section{Mở đầu}

Cây lúa (Oryza sativa L.) là một trong những loại cây trồng có nhu cầu nước lớn, để sản xuất $1 \mathrm{~kg}$ thóc cần đến 2500 lít nước [2]. Thực tế cho thấy, canh tác lúa nước sử dụng đến $80 \%$ tổng lượng nước tưới trong nông nghiệp [2]. Trong khi đó, theo dự báo của Bộ Tài nguyên và Môi trường (2007), do ảnh hưởng của biến đổi khí hậu, Việt Nam sẽ bị thiếu nước trầm trọng trong 50 năm tới. Hạn hán là một trong những nguyên nhân dẫn đến suy giảm năng suất lúa trầm trọng [7]. Theo Kumar và cộng sự [8], năng xuất lúa trong điều kiện hạn nặng có thể giảm đến $65 \%$ so với tưới đủ nước. Lúa là một trong những cây trồng chiếm vị trí quan trọng trong nền kinh tế với diện tích gieo trồng chiếm $56 \%$ tổng diện tích gieo trồng cây hàng năm [9]. Trong những năm qua, mặc dù năng suất lúa ở những vùng có tưới đã tăng gấp 2 đến 3 lần so với 30 năm trước đây, nhưng ở vùng canh tác nhờ nước trời năng suất tăng lên ở mức rất nhỏ, bởi vì sử dụng giống lúa cải tiến ở những vùng này rất khó khăn do môi trường không đồng nhất và biến động, hơn nữa tạo giống chịu hạn thích nghi cho điều kiện khó khăn này còn rất hạn chế [10]. Bắc Trung Bộ có tới 54,7\% diện tích là vùng đồi núi [11], điều kiện canh tác nông nghiệp còn nhiều khó khăn với phần lớn đất nông nghiệp là đất dốc không chủ động tưới. Sản xuất lúa gặp nhiều khó khăn, mùa đông (mùa khô) có khí hậu lạnh, khô gây nguy có sương giá, hạn hán nặng cho các loại cây trồng vì độ ẩm rất thấp $(<30 \%$, thậm chí $<15 \%)$, mùa hè nắng nóng kèm theo những đợt hạn ngắn ảnh hưởng rất lớn đến năng suất. Do đó, để nâng cao khả năng thích ứng với biến đổi khí hậu, đặc biệt là hạn hán và bảo đảm phát triển bền vững lĩnh vực nông nghiệp, việc nghiên cứu đánh giá lựa chọn các giống lúa chịu hạn cho các vùng khô hạn hoặc thiếu nước là hết sức quan trọng.

\footnotetext{
${ }^{1}$ Trường Đại Học Hồng Đức, Thanh Hóa

${ }^{2}$ Văn phòng Chương trình khoa học và công nghệ cấp quốc gia về tài nguyên môi truò̀ng và biến đổi khi hậu, Bộ Tài Nguyên và Môi trường

Email: lethihuongnl@hdu.edu.vn
} 
2. Vật liệu và phương pháp nghiên cứu

2.1. Vật liệu nghiên cứu
Thí nghiệm tiến hành nghiên cứu khả năng chịu hạn và năng suất của 8 giống lúa lai, bao gồm:

Bảng 1. Nguồn gốc các giống lúa thí nghiệm

\begin{tabular}{|c|c|}
\hline Giống lúa & Xuất xứ \\
\hline D ии 527 & Nhập nội từ Trung Quốc. \\
\hline Nhị U’u 69 & $\begin{array}{l}\text { Công ty } \mathrm{CP} \text { giống cây trồng Miền Bắc và Công ty TNHH Dịch vụ } \\
\text { Nông nghiệp Trọng Tín chọn tạo. Bộ NN-PTNT công nhận cho sản } \\
\text { xuất thử tại các tỉnh phía Bắc theo QĐ số } 54 \text { QĐ/BNN-PTNT ngày } \\
08 / 01 / 2007 \text {. }\end{array}$ \\
\hline Nhị U’u 89 & $\begin{array}{l}\text { Công ty TNHH Khoa học kỹ thuật giống cây trồng Đắc Nguyệt, Tứ } \\
\text { Xuyên, Trung Quốc chọn tạo. }\end{array}$ \\
\hline Nhị Uu 838 & $\begin{array}{l}\text { Công ty TNHH khoa học kỹ thuật giống cây trồng Chúng Trí, Tứ } \\
\text { Xuyên, Trung Quốc sản xuất. }\end{array}$ \\
\hline$Z Z D 001$ & $\begin{array}{l}\text { Công ty TNHH khoa học kỹ thuật giống cây trồng Chúng Trí, TP } \\
\text { Thành Đô, tỉnh Tứ Xuyên, Trung Quốc lai tạo và sản xuất. Giống đã } \\
\text { được BNN-PTNT công nhận chính thức tháng 10/2013. }\end{array}$ \\
\hline Thái xuyên 111 & $\begin{array}{l}\text { Công ty TNHH Nông nghiệp Công nghệ cao - Trường ĐHNN Tứ } \\
\text { Xuyên Trung Quốc với Công ty CP Tống Công ty giống cây trồng } \\
\text { Thái Bình, được công nhận giống Quốc gia năm } 2010 \text {. }\end{array}$ \\
\hline Nghi hwong & Công ty TNHH Khoa học kỹ thuật Giống cây trồng Đắc Nguyệt - \\
\hline 2308 & $\begin{array}{l}\text { Tứ Xuyên - Trung Quốc chọn tạo. Giống được Bộ NN-PTNT công } \\
\text { nhận theo QĐ số } 3277 \text { QĐ/BNN-KHCN ngày 23/11/2005. }\end{array}$ \\
\hline VT404 & Nhập nội từ Trung Quốc. \\
\hline
\end{tabular}

\subsection{Phạm vi nghiên cứu}

Thí nghiệm trong phòng được tiến hành ở Trung tâm thí nghiệm thực hành, Trường Đại học Hồng Đức, Thanh Hóa. Thí nghiệm đồng ruộng được bố trí ở các huyện miền núi thuộc 3 tỉnh Thanh Hóa, Nghệ An, Hà Tĩnh trong vụ xuân và vụ mùa 2017.

\subsection{Phương pháp bố trí thí nghiệm}

\subsubsection{Thi nghiệm trong phòng}

Đánh giá khả năng chịu hạn của giống lúa ở giai đoạn nảy mầm trong điều kiện hạn nhân tạo:

- Xác định tỷ lệ nảy mầm: gieo 30 hạt trong dung dịch Polyethylen glycol 20\% trên đĩa Petri, mỗi công thức bố trí 03 lần nhắc lại, sau 07 ngày đếm số hạt nảy mầm trên số hạt đem gieo. Tỷ lệ nảy mầm = Tỷ lệ cây mọc/tỷ lệ cây gieo (\%).

- Xác định sự phát triển của mầm và rễ trong điều kiện gây hạn: hạt giống được ủ nảy mầm, chọn những hạt có mầm dài $1 \mathrm{~cm}$ cuộn trong giấy thấm nhúng dung dịch Polyethylen glycol 20\%.
Sau 7 ngày đo chiều dài của mầm và rễ [1]. Sau đó so sánh với chiều dài mầm, rễ của công thức đối chứng.

2.3.2. Đánh giá khả năng chịu hạn của các giống lúa ngoài đồng ruộng

Thực hiện theo Quy chuẩn kỹ thuật Quốc gia về khảo nghiệm giá trị canh tác và sử dụng của giống lúa (QCVN 01-55:2011/BNNPTNT). Thí nghiệm được bố trí tại 3 tỉnh Bắc Trung Bộ bao gồm Thanh Hóa, Nghệ An và Hà Tĩnh ở vụ xuân và vụ mùa 2017. Lượng mưa trung bình vụ xuân đạt trung bình $68,9 \mathrm{~mm} /$ tháng, vụ mùa đạt 223,6mm/tháng (Bảng 2). Thí nghiệm được bố trí theo kiểu khối ngẫu nhiên đầy đủ với 3 lần nhắc lại, diện tích ô thí nghiệm là $20 \mathrm{~m}^{2}$. Lượng phân bón áp dụng cho 1 ha ở mức $90 \mathrm{~kg} \mathrm{~N}, 80 \mathrm{~kg}$ $\mathrm{P}_{2} \mathrm{O}_{5}$ và $80 \mathrm{~kg} \mathrm{~K} \mathrm{~K}_{2} \mathrm{O}$. Tính chịu hạn đồng ruộng được đánh giá thông qua các đặc điểm nông sinh học, năng suất và các yếu tố cấu thành năng suất của các giống lúa thí nghiệm. 
Bảng 2. Lượng mưa trung bình các tháng trong năm 2017

\begin{tabular}{lllllllllllll}
\hline Tháng & $\mathbf{1}$ & $\mathbf{2}$ & $\mathbf{3}$ & $\mathbf{4}$ & $\mathbf{5}$ & $\mathbf{6}$ & $\mathbf{7}$ & $\mathbf{8}$ & $\mathbf{9}$ & $\mathbf{1 0}$ & $\mathbf{1 1}$ & $\mathbf{1 2}$ \\
\hline $\begin{array}{l}\text { Lượng } \\
\begin{array}{l}\text { mưa TB } \\
(\mathrm{mm})\end{array}\end{array}$ & 16,5 & 18,7 & 53,3 & 68,0 & 188,6 & 149,7 & 203,3 & 245,0 & 310,5 & 209,5 & 93,1 & 33,5 \\
\hline
\end{tabular}

\subsection{Phương pháp xử lý số liệu}

Số liệu được xử lý và phân tích các thông số thống kê trên phần mềm Excel 2010 và IRRISTAT 5.0.

\section{Kết quả nghiên cứu và thảo luận}

3.1. Đánh giá khả năng chịu hạn của các giống lúa ở giai đoạn nảy mầm

Khả năng chịu hạn của các giống ở điều kiện hạn nhân tạo được xác định bởi tỷ lệ nảy mầm, độ dài của rễ và chồi mầm ở dung dịch Polyethylen glycol 20\%. Mức phản ứng của các giống lúa với dung dịch Polyethylen glycol 20\% là khác nhau. Giống có tỷ lệ nảy mầm cao và độ dài mầm, rễ dài thì khả năng chịu hạn càng cao và ngược lại. Kết quả cho thấy trong các giống thí nghiệm, giống lúa Thái Xuyên 111 và giống Nghi Hương 2308 có tỷ lệ nảy mầm cao, đạt lần lượt 89,33 và $87,77 \%$ trong điều kiện hạn nhân tạo. Chiều dài rễ và chồi mầm đạt cao nhất ở giống Thái Xuyên 111, thấp nhất là giống ZZD001 với tỷ lệ nảy mầm chỉ đạt $44,44 \%$, độ dài rễ và mầm lần lượt đạt 26,45 và $10,85 \mathrm{~mm}$ (Bảng 3).

Bảng 3. Tỷ lệ nảy mầm, độ dài rễ mầm và chồi mầm của các giống lúa lai trong điều kiện gây hạn nhân tạo

\begin{tabular}{|c|c|c|c|c|c|c|}
\hline \multirow[b]{2}{*}{ Tên giống } & \multicolumn{3}{|c|}{ Xử lý Polyethylen glycol 20\% } & \multicolumn{3}{|c|}{ Không xử lý } \\
\hline & $\begin{array}{c}\text { Tỷ lệ̀ nảy } \\
\text { mẩm } \\
(\%)\end{array}$ & $\begin{array}{c}\text { Độ dài rễ } \\
\text { mầm } \\
(\mathbf{m m})\end{array}$ & $\begin{array}{c}\text { Độ dài } \\
\text { chồi } \\
\text { mầm } \\
(\mathbf{m m})\end{array}$ & $\begin{array}{c}\text { Tỷ lệ nảy } \\
\text { mầm } \\
(\%)\end{array}$ & $\begin{array}{c}\text { Độ dài rễ̂ } \\
\text { mầm } \\
(\mathbf{m m})\end{array}$ & $\begin{array}{c}\text { Độ dài } \\
\text { chồi } \\
\text { mầm } \\
(\mathbf{m m})\end{array}$ \\
\hline Nhị ưu 838 & 73.33 & 38.50 & 26.50 & 86.33 & 38.70 & 31.90 \\
\hline Nhị ưu 69 & 81.11 & 46.60 & 30.45 & 96.67 & 55.85 & 34.35 \\
\hline Nghi hương 2308 & 87.77 & 42.47 & 30.40 & 91.12 & 50.50 & 32.14 \\
\hline VT404 & 81.11 & 48.65 & 29.30 & 93.33 & 53.70 & 32.45 \\
\hline D ưu 527 & 80.00 & 48.45 & 29.85 & 86.67 & 54.75 & 34.20 \\
\hline ZZD001 & 44.44 & 26.45 & 10.85 & 80.00 & 30.30 & 24.50 \\
\hline Nhị ưu 89 & 51.11 & 43.45 & 29.10 & 76.67 & 48.35 & 33.95 \\
\hline Thái Xuyên 111 & 89.33 & 50.35 & 31.40 & 94.65 & 51.20 & 36.30 \\
\hline
\end{tabular}

3.2. Kết quả đánh giá khả năng chịu hạn của các giống lúa lai thí nghiệm ngoài đồng ruộng

Các giống có thời gian sinh trưởng ngắn thuận lợi hơn trong việc bố trí thời vụ nhằm né hạn. Kết quả nghiên cứu cho thấy các giống lúa thí nghiệm có thời gian sinh trưởng dao động từ 120 đến 135 ngày trong vụ xuân và từ 104 đến 115 ngày trong vụ mùa. Trong đó giống có thời gian sinh trưởng ngắn nhất trong vụ xuân là Thái Xuyên 111 (121 ngày) và trong vụ Mùa là $\mathrm{D}$ ưu 527 (104 ngày) (Bảng 4). Nhìn chung, thời gian 
sinh trưởng của các giống lúa trong vụ mùa thường ngắn hơn vụ xuân. Nguyên nhân chủ yếu do vụ xuân ở Bắc Trung Bộ diễn ra từ tháng 1 đến tháng 5 là những tháng thường có nhiệt độ và lượng mưa trung bình thấp. Thời tiết lạnh và khô đầu vụ làm cho giai đoạn mạ bị kéo dài, cây sinh trưởng chậm hơn so với vụ mùa. Chiều cao cây của các giống lúa thí nghiệm thuộc nhóm trung bình, dao động từ 106,4 đến $118,7 \mathrm{~cm}$ trong vụ xuân và từ 103,9 đến 115,5cm trong vụ mùa. Theo Yoshida [12], các giống có chiều cao cây thấp có khả năng thích nghi cao hơn trong các điều kiện bất thuận, đặc biệt là trong điều kiện thiếu nước. Số nhánh/khóm có sự khác biệt rõ rệt giữa các giống thí nghiệm. Giống có số nhánh cao nhất là giống Thái Xuyên 111 với 7,75 nhánh/khóm trong vụ xuân và 7,42 nhánh/khóm trong vụ mùa, thấp nhất là giống $\mathrm{D}$ ưu 527 với lần lượt 6,41 nhánh/khóm và 6,19 nhánh/khóm (Bảng 4). Số nhánh có xu hướng giảm trong vụ mùa so với vụ xuân. Theo Yoshida [12], sự dao động về số nhánh chịu tác động của nhiều yếu tố, trong đó bao gồm mật độ cấy, phân bón, biện pháp chăm sóc và điều kiện ngoại cảnh. Ở thí nghiệm này, nguyên nhân suy giảm số nhánh trong vụ mùa có thể là do một số đợt hạn ngắn xuất hiện đầu tháng 7 làm ảnh hưởng đến khả năng đẻ nhánh của cây lúa.

Bảng 4. Một số đặc tính nông học của các giống lúa thí nghiệm

\begin{tabular}{lcccccc}
\hline & \multicolumn{3}{c}{ Vụ Xuân 2017 } & \multicolumn{4}{c}{ Vụ Mùa 2017 } \\
\cline { 2 - 7 } Giống & $\begin{array}{c}\text { Thời gian } \\
\text { sinh } \\
\text { trưởng } \\
\text { (ngày) }\end{array}$ & $\begin{array}{c}\text { Chiều } \\
\text { cao cây } \\
\text { (cm) }\end{array}$ & $\begin{array}{c}\text { Số } \\
\text { nhánh } \\
\text { /khóm }\end{array}$ & $\begin{array}{c}\text { Thời gian } \\
\text { sinh } \\
\text { trưởng } \\
\text { (ngày) }\end{array}$ & $\begin{array}{c}\text { Chiều } \\
\text { cao cây } \\
\text { (cm) }\end{array}$ & $\begin{array}{c}\text { Số } \\
\text { nhánh/ } \\
\text { khóm }\end{array}$ \\
\hline Nhị ưu 838 & 135 & $118.7^{\mathrm{c}}$ & $7.56^{\mathrm{c}}$ & 115 & $115.4^{\mathrm{d}}$ & $6.73^{\mathrm{ab}}$ \\
Nhị ưu 69 & 133 & $109.2^{\mathrm{ab}}$ & $7.79^{\mathrm{c}}$ & 110 & $107.8^{\mathrm{abc}}$ & $7.25^{\mathrm{bc}}$ \\
Nghi hương 2308 & 120 & $113.4^{\mathrm{b}}$ & $6.85^{\mathrm{ab}}$ & 106 & $115.5^{\mathrm{d}}$ & $7.23^{\mathrm{bc}}$ \\
VT404 & 125 & $110.5^{\mathrm{ab}}$ & $6.92^{\mathrm{b}}$ & 106 & $109.2^{\mathrm{bc}}$ & $6.22^{\mathrm{a}}$ \\
D ưu 527 & 123 & $106.4^{\mathrm{a}}$ & $6.41^{\mathrm{a}}$ & 104 & $103.9^{\mathrm{a}}$ & $6.19^{\mathrm{a}}$ \\
ZZD001 & 133 & $110.3^{\mathrm{ab}}$ & $6.53^{\mathrm{ab}}$ & 114 & $104.7^{\mathrm{ab}}$ & $6.47^{\mathrm{a}}$ \\
Nhị ưu 89 & 131 & $113.1^{\mathrm{b}}$ & $6.67^{\mathrm{ab}}$ & 113 & $110.7^{\mathrm{c}}$ & $6.64^{\mathrm{ab}}$ \\
Thái Xuyên 111 & 123 & $107.8^{\mathrm{a}}$ & $7.75^{\mathrm{c}}$ & 106 & $106.2^{\mathrm{ab}}$ & $7.42^{\mathrm{c}}$ \\
CV\% & & 6.8 & 6.5 & & 7.2 & 6.70 \\
LSD & & 5.2 & 0.5 & & 4.2 & 0.58 \\
\hline
\end{tabular}

Chú thích: Các chũ cái khác nhau thể hiện sụ sai khác ở mức có ý nghĩa 95\%

- Kết quả theo dõi thí nghiệm trong bảng 5 cho thấy số hạt trên bông có sự khác biệt rõ rệt giữa các giống lúa ở cả 2 vụ. Số hạt trên bông dao động từ 138,55 hạt/bông đến 160,7 hạt/bông trong vụ xuân và từ 116,2 đến 163,2 hạt/bông trong vụ mùa. Trong đó giống cho số hạt trên bông cao nhất ở cả 2 vụ là giống Thái Xuyên 111 , tiếp theo là giống Nhị Uu 89 và thấp nhất là giống D ưu 527. Tỷ lệ hạt chắc bình quân đạt cao hơn trong vụ xuân $(79,45 \%$ - 86,74\%) so với vụ mùa $(77,65 \%-83,41 \%)$.

- Trọng lượng 1000 hạt không có sự biến động lớn giữa 2 vụ, đây là đặc tính phụ thuộc chủ yếu vào giống. Trong các giống lúa thí nghiệm, giống ZZD001 có trọng lượng hạt cao nhất, đạt lần lượt $32,2 \mathrm{~g}$ và $32,0 \mathrm{~g}$ trong vụ xuân và vụ mùa. Giống có trọng lượng 1000 hạt thấp nhất là giống Thái Xuyên 111 (lần lượt là $25,7 \mathrm{~g}$ và 
25,3g) (Bảng 5).

- Năng suất được cấu thành chủ yếu bởi 3 yếu tố: số nhánh hữu hiệu (số bông/m2); số hạt chắc/bông và trọng lượng 1000 hạt của giống. Kết quả theo dõi năng suất của các giống lúa thí nghiệm cho thấy trong điều kiện không chủ động tưới, năng suất của các giống có sự khác nhau về mặt thống kê ở mức ý nghĩa 95\%. Trong đó, giống lúa Thái Xuyên 111 có số nhánh nhiều, số hạt/bông và tỷ lệ hạt chắc cao nên cho năng suất cao nhất so với các giống còn lại ở cả 2 vụ (lần lượt là 72,33 tạ/ha và 70,55 tạ/ha trong vụ xuân và vụ mùa), tiếp đến là giống Nhị Uu 838 . Năng suất thấp nhất ở vụ xuân thu được ở giống $\mathrm{D}$ ưu 527 với 53,03 tạ/ha và ở vụ mùa là giống VT404 với 53,27 tạ/ha (Bảng 5). Nhìn chung, các giống lúa lai thí nghiệm có năng suất bình quân thấp hơn so với các vùng đồng bằng chủ động tưới tiêu. Nguyên nhân là do thí nghiệm tiến hành ở vùng đồi núi Bắc Trung bộ, nơi chủ yếu phụ thuộc nước trời và điều kiện canh tác còn nhiều khó khăn nên chưa phát huy được hết tiềm năng của giống. Tuy nhiên, giống Thái Xuyên 111 vẫn cho năng suất khá. Điều đó cho thấy khả năng thích nghi của giống Thái Xuyên 111 với điều kiện khô hạn là khá tốt. Nhìn chung, năng suất của các giống lúa thí nghiệm trong vụ xuân cao hơn vụ mùa, nguyên nhân do sự khác biệt về điều kiện thời tiết khí hậu của 2 vụ. Theo Gana [4], thời gian hạn và giai đoạn sinh trưởng của cây là 2 yếu tố chính ảnh hưởng đến sự suy giảm về năng suất hạt. Đối với lúa, hạn hán xảy ra ở giai đoạn đẻ nhánh và sinh trưởng sinh thực thường gây thiệt hại nhất đến năng suất. Hạn hán ở giai đoạn mạ trong vụ xuân không ảnh hưởng nhiều đến năng suất do cây có thời gian phục hồi trước khi bước vào giai đoạn sinh trưởng sinh thực. Trong khi đó hạn xảy ra ở giai đoạn đẻ nhánh trong vụ mùa đã ảnh hưởng trực tiếp đến năng suất lúa, dẫn đến sự suy giảm về năng suất của các giống lúa thí nghiệm.

Bảng 5. Năng suất và các yếu tố cấu thành năng suất của các giống lúa thí nghiệm tại vùng đồi núi Bắc Trung Bộ

\begin{tabular}{|c|c|c|c|c|c|c|c|c|}
\hline \multirow[b]{2}{*}{ Giống } & \multicolumn{4}{|c|}{ Vụ Xuân 2017} & \multicolumn{4}{|c|}{ Vụ Mùa 2017} \\
\hline & $\begin{array}{l}\text { Số } \\
\text { hạt/bô } \\
\text { ng }\end{array}$ & $\begin{array}{l}\text { Tỷ lệ } \\
\text { hạt } \\
\text { chắc } \\
\text { (\%) }\end{array}$ & $\begin{array}{l}\text { Trọng } \\
\text { Lượng } \\
1000 \\
\text { hạt (g) }\end{array}$ & $\begin{array}{l}\text { Năng } \\
\text { suất } \\
\text { (tạ/ha) }\end{array}$ & $\begin{array}{l}\text { Số } \\
\text { hạt/bôn } \\
\text { g }\end{array}$ & $\begin{array}{l}\text { Tỷ lệ } \\
\text { hạt } \\
\text { chắc } \\
\text { (\%) }\end{array}$ & $\begin{array}{l}\text { Trọng } \\
\text { Lượng } \\
1000 \\
\text { hạt (g) }\end{array}$ & $\begin{array}{l}\text { Năng } \\
\text { suất } \\
\text { (tạ/ha) }\end{array}$ \\
\hline Nhị ưu 838 & 151.25 & 79.45 & 27.2 & $65.69^{c}$ & 149.5 & 77.65 & 27.5 & $63.53^{\mathrm{b}}$ \\
\hline Nhị ưu 69 & 154.9 & 83.2 & 26.4 & $63.20^{\mathrm{bc}}$ & 142.7 & 79.38 & 26.0 & $62.50^{\mathrm{b}}$ \\
\hline Nghi hương 2308 & 150.28 & 82.05 & 29.1 & $59.41^{\mathrm{ab}}$ & 146.8 & 82.37 & 28.5 & $54.47^{\mathrm{a}}$ \\
\hline VT404 & 138.55 & 83.06 & 27.7 & $55.67^{\mathrm{a}}$ & 128.5 & 80.36 & 27.1 & $53.27^{\mathrm{a}}$ \\
\hline D ưu 527 & 143.15 & 82.13 & 28.0 & $53.03^{\mathrm{a}}$ & 116.2 & 80.13 & 27.8 & $54.75^{\mathrm{a}}$ \\
\hline ZZD001 & 144.08 & 80.00 & 32.2 & $56.50^{\mathrm{a}}$ & 142.2 & 80.30 & 32.0 & $55.8^{\mathrm{a}}$ \\
\hline Nhị ưu 89 & 159.5 & 84.62 & 28.5 & $63.35^{\mathrm{bc}}$ & 153.6 & 79.23 & 28.2 & $62.43^{\mathrm{b}}$ \\
\hline Thái Xuyên 111 & 160.7 & 86.74 & 25.7 & $72.33^{d}$ & 163.2 & 83.41 & 25.3 & $70.55^{\mathrm{c}}$ \\
\hline CV\% & & & & 7.4 & & & & 6.9 \\
\hline $\operatorname{LSD}_{0.05}$ & & & & 5.8 & & & & 5.6 \\
\hline
\end{tabular}

Chú thích: Các chũ cái khác nhau thể hiện sụ sai khác ở mức có ý nghĩa 95\% 


\section{BÀI BÁO KHOA HỌC}

\section{Kết luận}

- Trong điều kiện gây hạn nhân tạo, giống Thái Xuyên 111 và Nghi Hương 2308 có tỷ lệ nảy mầm cao, mầm và rễ vẫn phát triển tốt, cho thấy đây là 2 giống có khả năng chịu hạn tốt ở giai đoạn nảy mầm.
- Giống Thái Xuyên 111 là giống có thời gian sinh trưởng trung bình, chịu hạn tốt, cho năng suất khá ở điều kiện không chủ động tưới. Năng suất lúa đạt 72,33 tạ/ha trong vụ xuân và 70,55 tạ/ha trong vụ mùa. Đây là giống có tiềm năng để đưa vào gieo cấy cho các vùng đồi núi khó khăn về nước tại Bắc Trung Bộ.

Lời cảm ơn: Nhóm nghiên cúu xin cảm ơn Văn phòng Chuơng trình khoa hoc và công nghệ cấp quốc gia về tài nguyên môi truờng và biến đổi khí hậu - Bộ Tài Nguyên và Môi truờng đã tài trợ kinh phí và hỗ trọ" khoa hoc trong quá trình thưc hiện đề tài: "Nghiên cứu, úng dụng công nghệ tiên tiến phục vu sản xuất nông nghiệp cho cácc vùng đồi núi Bắc Trung Bộ thích ứng với biến đổi khí hậu”, Mã số: BĐKH.01/16-20.

\section{Tài liệu tham khảo}

1. Adkins, S.W., Kunanuvatchaidach, R., Godwin, I.D., (1995), Somaclonal variation in rice drought-tolerance and other agronomic characters. Aust. J. Bot. 4, 201-209.

2. Bouman, B., (2009), How much water does rice use? Rice Today, 8, 28-29.

3. Bộ Nông nghiệp và Phát triển nông thôn (2011), Quy chuẩn kỹ thuật Quốc gia về Khảo nghiệm giá trị canh tác và giá trị sử dụng giống lúa. QCVN 01-55:2011/ BNNPTNT.

4. Gana, A., (2011), Screening and resistance of traditional and improved cultivars of rice to drought stress at Badeggi, Niger State, Nigeria. Agriculture and Biology Journal of North America, 2 (6), 1027-1031.

5. Nguyễn Văn Viết (2011), Một số biện pháp và chính sách ứng phó với biến đổi khi hậu của ngành nông nghiệp Việt Nam. Hội thảo lần thứ 2 về Biến đổi khí hậu toàn cầu giải pháp ứng phó của Việt Nam.

6. Hien, V.T., Nang, N.T., (2013), Results of Morphological Characteristics and Individual Yields of Rice Accessions on Artificially Dry Treated Conditions in Three Sensitive Stages. J. Sci. Dev. 11 (8), 81-91.

7. Hu, H.H., Xiong, L.Z., (2014), Genetic engineering and breeding of drought-resistant crops.Annu. Rev. Plant Biol. 65, 715-741.

8. Kumar, A., Bernier, J., Verulkar, S., Lafitte, H.R., Atlin, G.N., (2008), Breeding for Drought Tolerance: Direct Selection for Yield, Response to Selection and Use of Drought-Tolerant Donors in Upland and Lowland-Adapted Populations. Field Crops Research, 107 (3), 21-31.

9. Trần Thị Lệ, Nguyễn Thị Vân (2019), Nghiên cưu ảnh huởng của các múc phân bón và lương giống gieo đến sinh truởng, phát triển và năng suất giống lúa thuần DCG72 tại tỉnh Quảng Ngãi, Tạp chí khoa học và công nghệ nông nghiệp, 3, 23-33.

10. Nguyễn Văn Viết (2011), Một số biện pháp và chính sách ứng phó với biến đổi khí hậu của ngành nông nghiệp Việt Nam. Hội thảo lần thứ 2 về Biến đổi khí hậu toàn cầu giải pháp ứng phó của Việt Nam.

11. Tổng cục thống kê (2014), Niên giám thống kê Quốc gia năm 2014.

12. Yoshida, S., (1981), Fundamental of Rice Crop Science. International Rice Research Institute, Los Baños, Laguna, Philippines, 269. 


\section{BÀI BÁO KHOA HỌC}

THE EVALUATION OF DROUGHT TOLERANCE OF HYBRID RICE VARIETIES FOR CLIMATE CHANGE ADAPTATION IN MOUNTAINOUS AREAS IN NORTH

\section{CENTRAL, VIETNAM}

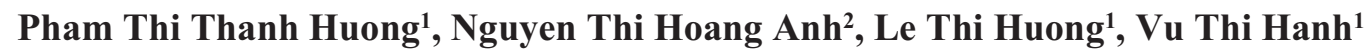

${ }^{1}$ Hong Duc University, Thanh Hoa

${ }^{2}$ Office of Science and Technology National Program for environmental resources and climate change, Ministry of Natural Resources and Environment

Abstract: The study was carried out in 2017 to study the morphological and yield responses of eight hybrid rice varieties to drought stress. Drought tolerance was tested using Polyethylene glycol 20\% for seed treatment. The growth and yield of the rice varieties were then estimated in rainfed field experiments in Thanh Hoa, Nghe An and Ha Tinh provinces. Results showed that drought has affected morphological and yield of these varieties. Among the varieties, Thai Xuyen 111 had the highest germination rate when treated with Polyethylene glycol 20\%. It also had average growth duration, good drought tolerance, and highest yields of 72,33 and 70,55quintal/ha in Spring and Summer seasons under rain-fed system, respectively.

Keywords: Hybrid rice, drought tolerant varieties, North Central, rain-fed area. 